\title{
The Eighteenth Rideal Conference on Chemisorption and Catalysis at the Fritz-Haber-Institut der Max-Planck- Gesellschaft Berlin 25-27 March 2015
}

\author{
Martyn V. Twigg1
}

Published online: 24 March 2016

(c) Springer Science+Business Media New York 2016

The Rideal Conferences had their origin in 1962 when Professor Charles Kemball organized a symposium at Queen's University in Belfast during the week before Easter to honor his former Cambridge PhD supervisor Sir Eric Rideal. At that time Rideal was at Imperial College where he had been since retiring from the Chair of Physical Chemistry at King's College London in 1955. The title of the symposium was "Chemisorption and Catalysis" and it was very successful with some eighty invited eminent delegates entering into extended friendly discussion and debate about the latest research results in areas largely pioneered by Rideal. A second conference along the same lines was organized 3 years later by Professor Frank Stone at the University of Bristol, and 3 years after that another of Rideal's former Cambridge PhD students, Professor Dan Eley, organized a similar conference at the University of Nottingham and it was there the name "Rideal Conference" was adopted. Further Rideal Conferences have been held in the week before Easter whenever possible every 3 years.

Professor Kemball's symposium was in Northern Ireland and most of the Conferences that followed were held in mainland UK with the exception of one at University College Dublin in 1986 organized by Professor John Clarke. Although Sir Eric Rideal obtained his $\mathrm{PhD}$ at the University of Bonn in Germany and he spent a lot of time visiting America it is surprising there has not been a Rideal Conference in continental Europe or in America. The most recent conference broke this tradition by moving into

Martyn V. Twigg

marsarbooks@yahoo.co.uk

1 Twigg Scientific \& Technical Ltd, Caxton, Cambridge CB23 3PQ, UK
Europe, and appropriately to Germany. The eighteenth Rideal Conference was held at The Fritz-Haber-Institut der Max-Planck-Gesellschaft in Berlin during 25-27 March 2015 (Fig. 1).

The honorary chairman of the Organizing Committee was the 2007 Chemistry Nobel Prize winner Professor Gerhard Ertl and the senior local organizer was Professor Hans-Joachim Freund who was ably assisted by Manuela Misch with administration and Daniela Nickolaus during the Conference. All of the arrangements progressed smoothly and the Conference Dinner was held in the roof garden restaurant in the German Bundestag, the Lower House of the German Parliament. The title of the Conference was "Roles of Catalysis and Catalytic Processes as World Energy and Feedstock Sources Change" and there were six oral sessions each with four speakers and there was also a poster session with many interesting contributions.

\section{The First Session}

The conference began with a Memorial Session in honor of Professor Wyn Roberts (Cardiff University) who was a strong supporter of the Rideal Conferences. He organized one at the University of Bradford in 1983, and it was he who originally suggest having a Conference in Berlin. This Session was attended by the wife of Professor Roberts Angharad Roberts and their daughter Mrs Karen Page.

The first presentation was a tribute to Professor Roberts entitled "A Significant Life Journey in Surface Science" by his friend since school in South Wales, Professor Sir John Meurig Thomas (University of Cambridge) that was delivered by the present author and included a video interview with Sir John about the life and scientific achievements of Professor Roberts. 


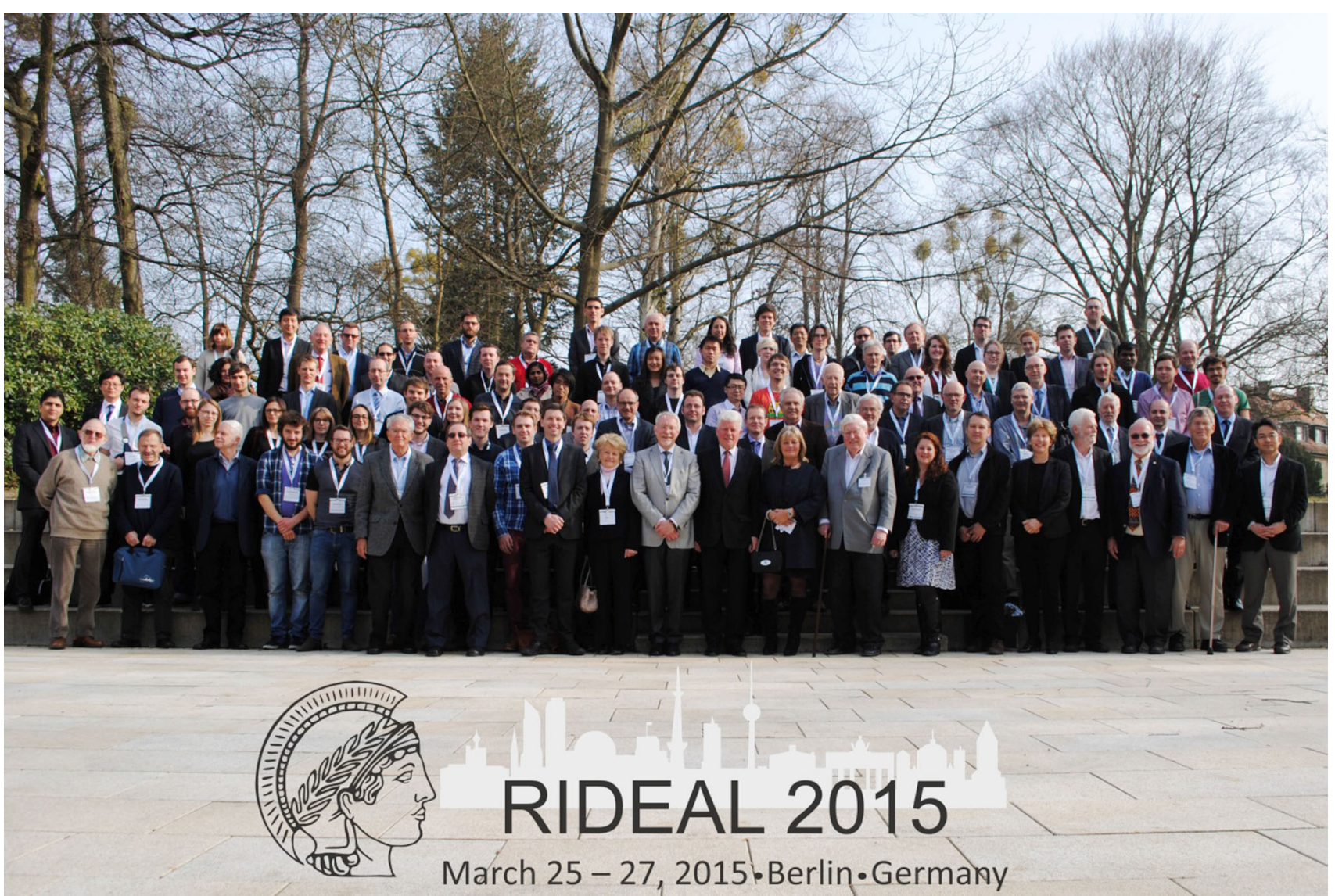

Fig. 1 Delegates at the eighteenth Rideal Conference held at The Fritz Haber Institute, Berlin, 25-27 March 2015

The Session continued with talks by Professor Roberts' former colleagues. Professor Graham Hutchings (Cardiff University) discussed methane activation by selective oxidation with hydrogen peroxide catalysed by the iron exchanged zeolite FeZSM5. The initial product, methyl hydroperoxide, decomposes to give methanol that undergoes further oxidation to formic acid and addition of copper inhibits the latter reaction.

Very much in keeping with Rideal's interests, Professor Michael Bowker (Cardiff University) examined the roles of precursor states in surface adsorption and catalysis on crystal planes and model supported catalysts. This contribution probed the intimate mechanistic details of these fundamental processes.

The last contribution in this Session by Professor Philip R. Davies (Cardiff University) reviewed the role of water in heterogeneous catalysis, thus revisiting the topic of Professor Roberts' final paper (Catalysis Letters, 2014, 144, 767). Some of Roberts' ideas were explored in the broader context of recent advances. At levels below which site blocking is significant, water can have surprisingly large effects on reaction rates and of course the roles of surface hydroxyl groups were highlighted. The Session as a whole was a very fitting tribute to the late Professor Wyn Roberts.

\section{The Second Session}

This Session was about the environmentally important area of "Automotive Catalysis". Control of tailpipe emissions from gasoline and diesel powered vehicles by catalytic systems has developed tremendously since first introduced four decades ago, and in many places air quality has improved markedly as a result. Professor Galen Fisher (University of Michigan) began the Session by providing an overview of the area from the immensely polluting "gas guzzlers" of the early 1970s in America to the current SULEV (Super Ultra Low Emissions Vehicle) counterparts whose tailpipe emissions can be less polluting than the ambient air, illustrating the success three way catalysts (TWCs) have had in improving urban air quality. Progress with diesel powered vehicles has also been dramatic with their once obvious obnoxious soot emissions effectively controlled by the introduction of particulate matter (PM) filters often referred to as diesel particulate filters (DPFs). 
Often now PM emissions from diesel cars can be significantly below some gasoline cars, and similarly diesel NOx emissions are being effectively controlled, particularly by new selective catalytic reduction (SCR) systems that in Europe and elsewhere are fitted to heavy duty diesel (HDD) vehicles as well as to diesel cars.

Professor Enrico Tronconi (Politecnico di Milano, Italy) highlighted ammonia SCR reactions and their mechanisms over an amazingly active copper zeolite catalyst in various environments. Next Professor Andrea Strzelec (Texas A\&M University, USA) discussed some of the important reactions involved in periodic oxidation of soot in DPFs that returns the back-pressure across them to the normal operating range. The mechanistic differences resulting from the higher reactivity of nitrogen dioxide $\left(\mathrm{NO}_{2}\right)$ shrinking core behaviour was compared to the slower rate of reaction with of oxygen $\left(\mathrm{O}_{2}\right)$ that leads to further penetration of $\mathrm{O}_{2}$ into the pore structure.

Dr Andy Walker (Johnson Matthey. UK) concluded the Session with a review of current diesel emissions control technologies focusing on the HDD area highlighting practical aspects of emissions control and in particular of SCR NOx control that included how even low levels of ammonia slip into the atmosphere is prevented.

\section{The Third Session}

This Session mainly concerned oxide surfaces and catalysis on them. It was opened with a lecture by Professor Joachim Sauer (Humboldt-Universität Berlin, Germany) about C-H bond activation by transition metal oxides and the present understanding of support effects. Density functional theory calculations were used to suggest the most likely mechanism of methanol oxidation over $\mathrm{VO}_{\mathrm{x}} / \mathrm{CeO}_{2}(111)$ and $\mathrm{VO}_{\mathrm{x}} /$ $\mathrm{SiO}_{2}$ systems and reasons for the higher activity of the former were suggested.

This was followed by talk by Professor Geoff Thornton (University College, London) on the simulated near-edge $\mathrm{X}$-ray absorption fine structure (NEXAFS) measurements on a single carbon monoxide covered palladium nanoparticle supported on $\mathrm{TiO}_{2}(110)$ with an assumed truncated cuboctahedron shape. The strain on the nanoparticle induced by "carpet growth" across the substrate step-edges also weakens the $\mathrm{CO}-$ metal bond, which reduces the energy barrier for catalytic reactions, including $\mathrm{CO}$ oxidation.

Professor Gianfranco Pacchioni (Università degli Studi di Milano-Bicocca, Italy) then reported novel aspects of adsorption on two-dimensional insulators. Calculations combined with experimental evidence (mostly scanning tunneling microscopy) was presented on self-doping of two-layer $\mathrm{NaCl} / \mathrm{Au}(111)$ films when $\mathrm{Co}$ or $\mathrm{Cr}$ atoms are deposited on the surface; $\mathrm{Cr}$ and $\mathrm{Co}$ atoms spontaneously replace $\mathrm{Na}$ and $\mathrm{Cl}$ ions in the films changing the electronic and magnetic properties. It was shown two-dimensional crystalline $\mathrm{SiO}_{2} / \mathrm{Ru}(0001)$ films can selectively allow diffusion of adsorbed metal atoms or small molecules at the metal/insulator interface opening the way to the study of chemistry in unusually confined environments.

The next paper in this issue of Topics in Catalysis, by Professor Israel Wachs (Lehigh University, USA) and his coworkers, is about the ethylene polymerization catalyst known as "Phillips Catalyst" named after the company in which J. P. Hogan and R. L. Banks were during the early 1950s when they discovered ethylene can be polymerized by low levels of chromium on silica-alumina. This catalyst has been amazingly successful, yet in spite of its apparent simplicity it is not well characterized under operating conditions. Results from modern instrumental in situ techniques coupled with computational methods led to the conclusions that fresh catalyst contains two isolated $\mathrm{Cr}$ (VI) centers on silica, tetrahedral $(\mathrm{O}=)_{2} \mathrm{CrO}_{2}$, and distorted square pyramidal $\mathrm{O}=\mathrm{CrO}_{4}$. These activate at different rates during reaction with ethylene and two surface $\mathrm{Cr}(\mathrm{III})$ intermediates were identified: $\mathrm{Cr}(\mathrm{III})-\mathrm{CH}=\mathrm{CH}_{2}$ which is active in polymerization and $\mathrm{Cr}(\mathrm{III})-\left(\mathrm{CH}_{2}\right)_{2} \mathrm{CH}=\mathrm{CH}_{2}$ which may be a spectator intermediate.

\section{The Forth Session}

Sir Eric Rideal was interested in photochemistry and one of his PhD students, Ronald G. W. Norrish, worked on the photolysis of potassium permanganate (1923), and in 1967 he shared the Chemistry Nobel Prize with George Porter and Manfred Eigen for work on fast reactions-in his case flash photolysis. The Forth Session, which centered on photochemistry, began with Professor Cynthia M. Friend (Harvard University, USA) talking about the photo-oxidation of methanol and formaldehyde on Rutile, $\mathrm{TiO}_{2}(110)$. The roles of defects in transition metal oxide photochemistry were highlighted using a combination of experimental results and theory to understand how photo-excitation leads to specific reactions. Key factors are the electronic structure of the photo-material, the nature of bonding involved, the excited states of reactant molecules, as well as the rate of electron-hole pair recombination.

Professor Ryu Abe (Kyoto University, Japan) continued the photochemical theme by discussing a fascinating solar visible light driven water splitting system based on porous $\mathrm{CoO}_{\mathrm{x}} / \mathrm{TaON}$ photoanodes fabricated on titanium metal. The co-catalyst $\mathrm{CoO}_{x}$ scavenges holes and prevents selfoxidative deactivation. The low cost of the materials involved might help the realization of practical applications. 
Professor Frank Osterloh (University of California at Davis, USA) then presented a systematic investigation of three types of the robust n-type semiconductor tungsten(VI) oxide $\left(\mathrm{WO}_{3}\right)$ in water splitting to determine the influence of particle size and morphology on photocatalytic oxygen evolution and photocurrent generation. It was concluded the activity differences are controlled not by energetics but by the kinetics of minority and majority carrier transport.

Professor Gabriele Centi (University of Messina, Italy) reviewed the use of solar energy to convert carbon dioxide into liquid fuels with high conversion efficiency solar photoelectrocatalytic (PEC) devices. Key is the coupling of fast charge separation with the very much slower processes of catalytic reduction and transport processes (especially at interfaces); much progress is needed in several areas before such devices are widely used.

\section{The Fifth Session}

The penultimate and fifth Session was on energy conversion and catalysis and Professor Robert Schlögl (Fritz-HaberInstitute, Berlin) began the Session by discussing catalysis in chemical energy conversion that will be required for the replacement of primary fossil fuels by alternative renewable energy sources. Biomass alone cannot replace fossil fuels so renewable electricity will have to be converted into material energy carriers. Reduction of carbon dioxide and of nitrogen are the most promising candidates that could be achieved using renewable hydrogen from electro- or photochemical sources or by direct photochemical or electrochemical conversion. Throughout this talk the important future roles of catalytic conversions were stressed.

Professor Avelino Corma (Universitat Politècnica de València, Spain) discussed ways of integrating several chemical reactions into single processes by developing multifunctional catalysts to conduct multistep process in a cascade mode, thereby reducing or eliminating intermediate separation and purification. It was shown by combining metal and oxide catalysts it is possible to photochemically convert carbon dioxide and water into hydrocarbons by combining basic supports and metal nanoparticles in an active and selective catalyst. Similar types of catalysts are also able to carry out photochemically the water gas shift reaction to produce hydrogen.

Professor Timo Jacob (Ulm University, Germany) then discussed the interface between gold electrodes and ionic liquids. The adsorption of 1-butyl-3-methyl-imidazolinium-hexafluorophosphate (BMI/PF6) on $\mathrm{Au}(100)$ was estimated for a range of surface coverages using DFT calculations. At low coverage BMI is mobile and lie flat on the surface, at higher coverages repulsion between BMIs are minimized while attractions between $\mathrm{BMI}^{+}$and $\mathrm{PF}_{6}^{-}$ are maximized by coordination of $\mathrm{PF}_{6}{ }^{-}$with positively charged imidazole carbons. At higher coverages adsorbate islands form in a checkerboard pattern of BMI and PF6, in a plane parallel to the surface, while at yet higher coverages BMI ions are twisted out of this plane. Finally adsorbed BMI stand end on in order to squeeze more adsorbates onto the surface.

Zeolite catalysts are particularly important in industrial processes and the final contribution in this Session, by Professor Bert Weckhuysen (Utrecht University, The Netherlands), discussed advances in spectro-microscopy of zeolite-based catalysts at different scales from single molecules and single atoms via individual catalyst particles to the level of the working reactor.

\section{The Sixth Session}

The final Session centered around methane activation and related catalysis that began with a presentation by Dr Peter Farnell (Johnson Matthey, UK) that highlighted a number of topics associated with the conversion of natural gas and other hydrocarbons to synthesis gas (mixtures of hydrogen and carbon oxides) that is used for manufacturing high volume products such as hydrogen, methanol and ammonia. The effect of catalyst poisons in the reactor feed as well as the potentially devastating effects of pyrolytic and whisker carbon formation on catalyst performance were covered. The very low effectiveness factors of traditional nickel-based steam reforming catalysts at higher temperatures enabled fabricated metal structures coated with catalyst formulations to be made that gave advantageous performance in terms of heat transfer and pressure-drop characteristics.

Vanadium pentoxide has long been used in commercial catalyst formulations for oxidation of sulphur dioxide for sulphuric acid production and the oxidation of organic compounds to maleic anhydride (from butane) and phthalic anhydride (from ortho-xylene or naphthalene). Vanadium pentoxide itself has a layer structure with the layers held together by van der Waals forces. Professor Horia Metiu (University of California at Santa Barbara, USA) described an experimental study on the structure and oxidizing power of single layers of vanadium pentoxide. The layer edges undergo reconstruction when an oxygen vacancy is formed and the charge of two vanadium atoms is reduced. The energy of this process is higher for the two-dimensional structures than for multilayers indicating two-dimensional structures are less aggressive oxidants than bulk vanadium pentoxide.

Dr Ekkehard Schwab (BASF, Ludwigshafen Germany) presented an overview of the industrial consequences of 
changing feedstocks and their costs. Until the early nineteenth century chemicals and energy were derived from renewables but the industrial revolution was fuelled by coal. Since then the chemical industry has been based on nonsustainable feedstocks, first coal then more attractive liquid hydrocarbons and natural gas. The appropriate catalysts and catalytic processes mainly depend on the feedstock used and this in turn mainly depends on its relative cost. As a result of feedstock price changes in recent years, there have been considerable new demands on existing catalysts and catalytic processes. Going forward, catalyst development will be important to provide competitive means of using sustainable feedstocks and new multifunctional catalysts capable of carrying out complex sequential reactions to improve operational efficiency.

Zirconia $\left(\mathrm{ZrO}_{2}\right)$ is usually considered an "inert" catalyst support but the final presentation in this Session and the last of the Conference given by Professor Leon Leffert (Aalto University, Finland) who reviewed the catalytic properties of $\mathrm{ZrO}_{2}$. The high temperature $\left(900{ }^{\circ} \mathrm{C}\right)$ catalytic partial oxidation of methane takes place by methane removing some surface lattice oxygen atoms in terraces and the reaction proceeds via a surface redox process.
Catalysis of the water-gas shift reaction most likely involves hydroxyl groups at defect sites generated by water dissociation, again highlighting their importance in catalysis over $\mathrm{ZrO}_{2}$. Surprisingly $\mathrm{H}_{2} \mathrm{~S}$ can enhance the catalytic performance of $\mathrm{ZrO}_{2}$, and DFT calculations were used to explain this behavior.

\section{Conclusions}

There were 108 delegates from academia and industry who came from 12 different countries at the Rideal Conference in Berlin. There were 24 oral presentations as well as 50 posters, and awards were made to the authors of six posters who were from four countries. To support younger scientists, bursaries were given to thirteen students from three countries. The traditional friendly atmosphere and ample time for constructive debates among delegates were obvious features of the present Conference, and all who attended the first Rideal Conference on continental Europe considered it a great success in all respects. This success, to a large extent, was facilitated by the helpfulness and warm hospitality given by members of the Fritz-Haber-Institute. 